\title{
How to improve repetition ability in patients with Wernicke's aphasia: the effect of a disguised task
}

\author{
M Otsuki, Y Soma, N Yoshimura, K Miyashita, K Nagatsuka, H Naritomi
}

J Neurol Neurosurg Psychiatry 2005;76:733-735. doi: 10.1136/jnnp.2003.028688

Dissociation "automatico-voluntaire" is a symptom observed in aphasic patients. We elucidated the difference between voluntary and involuntary speech output in a quantitative manner using the same task materials in nine patients with Wernicke's aphasia. All the patients exhibited better ability and less paraphasias in a repetition task elicited in a disguised condition than in an ordinary repetition condition. This result indicates that the output difficulty in Wernicke's aphasia might be a disability of volitional control over the language system.

$\mathrm{P}$ atients with aphasia usually exhibit instability in their language output, depending on context. The dissociation between voluntary and involuntary language is known as dissociation "automatico-voluntaire". ${ }^{1}$ Benson $^{2}$ pointed out that patients with Wernicke's aphasia often understand several words when first tested but may fail to comprehend additional words. This phenomenon is called "fatigue" or "jamming". Such fluctuation in language ability indicates that patients with aphasia have a better language ability than they actually manifest. This superior ability is demonstrated only under certain conditions. However, it remains unclear what kind of situation or context should be established for patients to demonstrate better language ability.

While dissociation automatico-voluntaire is well known, few studies have confirmed a difference in ability between voluntary and involuntary speech in a statistical fashion. There are some studies showing an advantage on nonpropositional (automatic) speech compared to propositional speech in aphasic patients, ${ }^{3}$ but not in Wernicke's aphasia. We demonstrate here the difference in ability between voluntary output and involuntary output in patients with Wernicke's aphasia in a quantitative manner.

\section{METHODS \\ Subjects}

The subjects were nine right handed patients (five males and four females) with focal lesions due to cerebrovascular accident, who were clinically diagnosed with Wernicke's aphasia according to established criteria. ${ }^{2}$ The patients showed poor auditory comprehension and fluent speech contaminated with various types of paraphasic errors. The profiles of the patients and the results of neuropsychological assessments are shown in table 1. The findings on computed tomography (CT) or magnetic resonance imaging (MRI) of all patients are shown in fig 1 . All patients demonstrated lesions in the left temporal lobe and/or parietal lobe, in accord with the manifestation of Wernicke's aphasia. ${ }^{2}$

\section{Tasks}

We administered word repetition tasks under two conditions using the same sets of 40 common words (nouns). One was an ordinary word repetition task, in which patients were requested to repeat auditorily presented words; the other was a disguised repetition task, in which patients were requested to point to a corresponding figure among 10 choices after the auditory presentation of words. Before the disguised task, we recommended that the patients repeat each word before searching the drawings. We did not inform them that their repetition ability would be assessed in the disguised task. We prepared five different plates each showing 10 line drawings for choices, and showed each plate at random at each word. The choices did not necessarily include a drawing of the target drawings representing words, in fact on average only $20 \%$ of the plates presented had drawings representing the target words. For scoring of repetition ability elicited in the disguised condition, a silent reaction or lack of repeating words was regarded as an incorrect response, and we did not count correct words elicited after drawings were found in order to avoid counting naming ability. We assessed only phonologically correct words repeated while searching the drawings as correct responses in the disguised task. We only counted the first responses and not later responses in both the ordinary repetition and the disguised tasks. The results of the disguised task, therefore, almost exactly reflect the implicit repetition ability of the patients, since they paid primary attention to searching for the correct drawing among the choices.

We administered these two tasks using the same set of 40 words for each task in a counterbalanced order such as ABBA. We gave all patients the target words at the same rate of every $5 \mathrm{~s}$. We compared the correct repetition numbers or percentages between the two conditions.

\section{RESULTS}

The profiles of the patients, the results of neuropsychological assessments, and the results of the two tasks are shown in table 1.

The patients showed a significantly better ability to repeat single words with fewer phonological errors in the disguised task than in the ordinary repetition task (table 1, last two lines). The results proved that patients showed a significantly better ability to repeat words elicited in the disguised condition. Only $20 \%$ of the plates presented drawings of the target words and these drawings proved to be useless because the patients showed no correct answers on these target words.

\section{DISCUSSION}

The ability to repeat single words in Wernicke's aphasia is often contaminated with phonological errors (phonemic paraphasia). Our results suggest that appropriate word output ability in Wernicke's aphasia can be improved in a disguised condition. Voluntarily repeating words paradoxically seems to interrupt word repetition. The essence of our disguised task is diversion of attention or concern from the target performance (repetition) to another task (searching drawings). The fact that patients with Wernicke's aphasia 


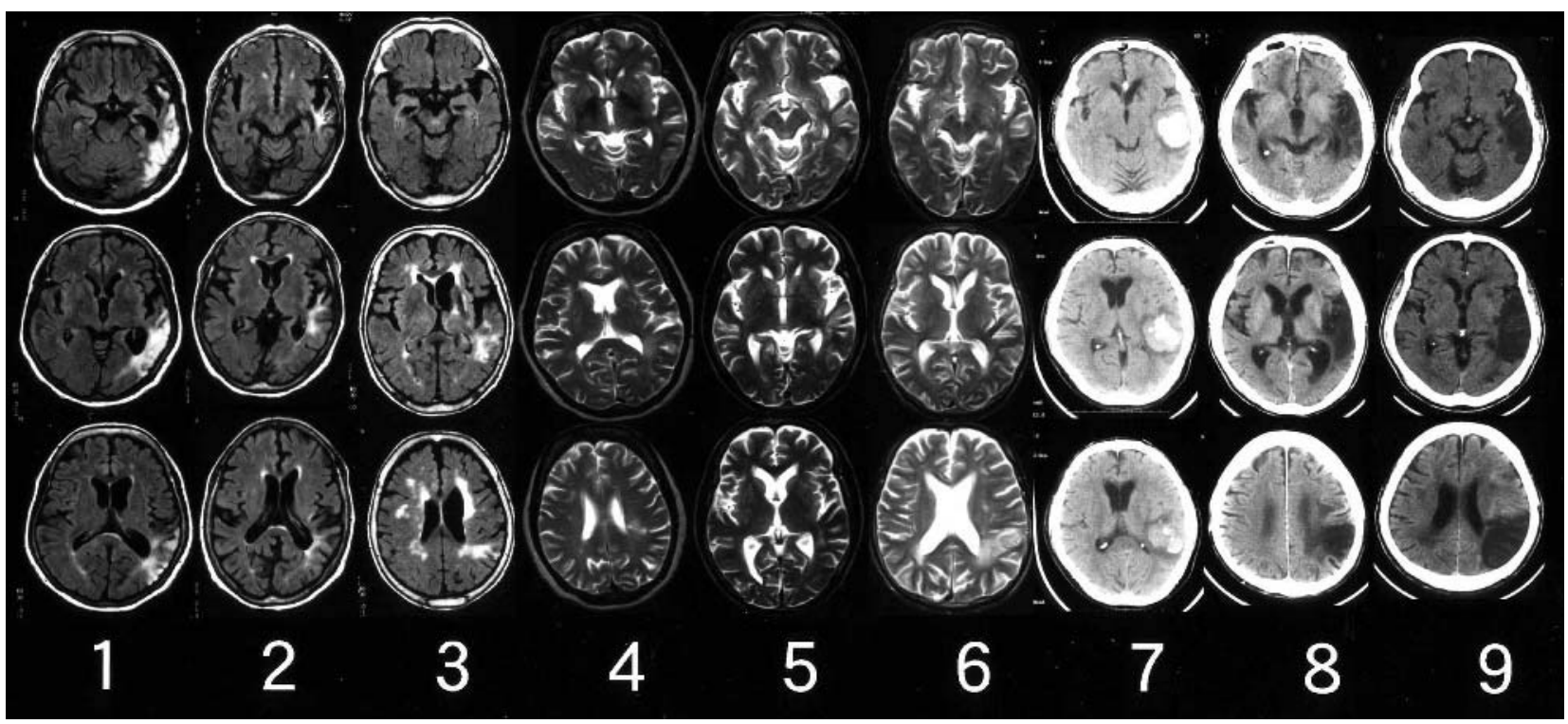

Figure 1 Images of the patients (MRI or CT).

implicitly comprehend words was shown by Milberg and Blumstein. ${ }^{4}$ In their study, the patients showed semantic priming (implicit semantic comprehension), even though they showed severe disturbance on semantic judgement tasks with explicit matter. Thus, it can be speculated that patients with Wernicke's aphasia have a better ability both in word input, as shown in the study of Milberg and Blumstein, ${ }^{4}$ and in output as shown in our study under disguised conditions.

The better repetition ability elicited in the disguised task seemed to be disclosed with the diversion of attention or concern from the target performance to another task. It remains unclear why this diversion can improve the subjects' output ability. It might be related to the dual process theory which evidenced a dissociation between automatic processing and controlled processing. ${ }^{5}$ It is considered that the output difficulty in Wernicke's aphasia is not a destruction of output ability per se, but might be a disability of volitional control over the language system. However, on the other hand, it is difficult to provide a full breakdown of phonological errors even in the disguised task because it seems nearly impossible to eliminate volition entirely. Thus, reducing or unloading damaged volition in these patients may be an important key for patients with Wernicke's aphasia to demonstrate their remaining language ability.

Table 1 Profiles of the patients, results of neuropsychological assessments, and results of the two tasks

\begin{tabular}{|c|c|c|c|c|c|c|c|c|c|}
\hline Patient & 1 & 2 & 3 & 4 & 5 & 6 & 7 & 8 & 9 \\
\hline Age & 64 & 80 & 82 & 58 & 70 & 77 & 74 & 71 & 64 \\
\hline Sex & $\mathrm{F}$ & $\mathrm{F}$ & $\mathrm{F}$ & $\mathrm{F}$ & $M$ & M & M & $M$ & M \\
\hline WAB & $44 \mathrm{D}$ & $5 \mathrm{D}$ & $18 D$ & $6 D$ & $17 D$ & $26 \mathrm{D}$ & $31 \mathrm{D}$ & $5 Y$ & $14 \mathrm{D}$ \\
\hline \multicolumn{10}{|l|}{ Spontaneous speech } \\
\hline Information content (10) & 7 & 8 & 3 & 3 & 9 & 6 & 1 & 6 & 5 \\
\hline Fluency (10) & 8 & 8 & 7 & 8 & 9 & 8 & 7 & 8 & 7 \\
\hline \multicolumn{10}{|l|}{ Comprehension } \\
\hline Yes/No question (60) & 48 & 53 & 50 & 41 & 52 & - & - & 15 & 51 \\
\hline Auditory word recognition (60) & 49 & 51 & 33 & 48 & 50 & 39 & 15 & 20 & 15 \\
\hline Sequential commands (80) & 32 & 26 & 0 & 22 & 12 & 0 & - & 0 & 10 \\
\hline Repetition (100) & 47 & 58 & 12 & 31 & - & 40 & 0 & 2 & 0 \\
\hline \multicolumn{10}{|l|}{ Naming } \\
\hline Object naming (60) & 24 & 11 & 9 & 23 & 38 & 14 & 0 & 3 & 0 \\
\hline Word fluency (20) & 4 & 2 & 0 & 2 & 5 & 1 & 0 & 0 & 0 \\
\hline Sentence completion (10) & - & 4 & 1 & 0 & 6 & 2 & 0 & 0 & 0 \\
\hline Responsive speech (10) & 6 & 2 & 3 & 8 & 6 & 4 & 0 & 0 & 0 \\
\hline Token test $(100 \%)$ & 66 & 63 & 30 & 43 & 16 & 27 & 18 & 28 & 1 \\
\hline RCPM (36) & 31 & 33 & 29 & 24 & 32 & - & - & 35 & - \\
\hline \multicolumn{10}{|l|}{ Correct numbers $(n=40)$} \\
\hline $\begin{array}{l}\text { Ordinary task } \\
\text { (percentage) }\end{array}$ & $\begin{array}{l}25 \\
(62.5)\end{array}$ & $\begin{array}{l}35 \\
(87.5)\end{array}$ & $\begin{array}{c}12 \\
(30.0)\end{array}$ & $\begin{array}{l}19 \\
(47.5)\end{array}$ & $\begin{array}{l}33 \\
(82.5)\end{array}$ & $\begin{array}{l}20 \\
(50.0)\end{array}$ & $\begin{array}{l}0 \\
(0.0)\end{array}$ & $\begin{array}{c}9 \\
(22.5)\end{array}$ & $\begin{array}{l}0 \\
(0.0)\end{array}$ \\
\hline $\begin{array}{l}\text { Disguised task } \\
\text { (percentage) }\end{array}$ & $\begin{array}{l}34 \\
(85.0)\end{array}$ & $\begin{array}{c}40 \\
(100.0)\end{array}$ & $\begin{array}{l}26 \\
(65.0)\end{array}$ & $\begin{array}{l}25 \\
(62.5)\end{array}$ & $\begin{array}{l}39 \\
(97.5)\end{array}$ & $\begin{array}{l}29 \\
(72.5)\end{array}$ & $\begin{array}{l}21 \\
(52.5)\end{array}$ & $\begin{array}{l}18 \\
(45.0)\end{array}$ & $\begin{array}{l}25 \\
(62.5)\end{array}$ \\
\hline
\end{tabular}

The numbers in parentheses in the first column are the full marks for each task.

We statistically compared the groups using paired $t$ tests. The correct number of answers in the disguised task was significantly greater in all patients (mean of the differences $=-11.5556$, standard deviation of the differences $=50.00278, t=4.90123$, degrees of freedom $=8$, level of significance $=0.119189 \times 10^{-2}$, $\mathrm{p}<0.01$ ).

D, days after onset; F, female; M, male; RCPM, Raven's Coloured Progressive Matrices; WAB, Western aphasia battery; Y, years after onset; -, not examined. 


\section{Authors' affiliations}

M Otsuki, School of Psychological Science, Health Sciences University of Hokkaido, Sapporo, Japan

Y Soma, Soma Neurology Clinic, Niigata, Japan

N Yoshimura, Department of Neurology, Takeda General Hospital, Aizuwakamatsu, Japan

K Miyashita, K Nagatsuka, H Naritomi, Cerebrovascular Medicine, National Cardiovascular Center, Osaka, Japan

Competing interests: none declared

Correspondence to: Mika Otsuki, School of Psychological Science, Health Sciences University of Hokkaido, 2-5 Ainosato, Kita-ku, Sapporo, Hokkaido, 002-8072, Japan; miotsuki@hoku-iryo-u.ac.jp
Received 23 September 2003

Revised version received 17 August 2004

Accepted 20 August 2004

\section{REFERENCES}

1 Alajouanine T. Baillarger and Jackson: the principle of Baillarger-Jackson in aphasia. J Neurol Neurosurg Psychiatr 1960;23:191-3.

2 Benson DF. Wernicke's aphasis. In: Aphasia, alexia and agraphia. New York: Churchill Livingstone, 1979:71-7.

3 Lum C, Ellis AW. Why do some aphasics show an advantage on some tests of nonpropositional (automatic) speech? Brain Lang 1999;70:95-118

4 Milberg W, Blumstein SE. Lexical decision and aphasia: evidence for semantic processing. Brain Lang 1981;14:371-85.

5 Birnboim S. The automatic and controlled information-processing dissociation: is it still relevant? Neuropsychol Rev 2003;13(1):19-31.

\section{NEUROLOGICAL PICTURE}

\section{Platysma sign in high cervical lesion}

$P$ latysma weakness has been acknowledged as a sign of central hemiparesis, particularly when facial paresis is not obvious. A 71 year old man-who had no history of Bell's palsy or stroke-had an acute onset of right side dominant tetraparesis, decreased superficial sensation below C3 segment, and micturitional disturbance. He also had platysma weakness on the right side (fig 1), though cranial nerves were normal. Magnetic resonance imaging (MRI) scans of the cervical cord disclosed a high signal intensity in the right side dominant central cord at C3-4 segments on $\mathrm{T} 2$ weighted image (fig 2), suggestive of the cervical cord infarction. Platysma muscles are innervated by both the facial nucleus and high cervical cord in mammals, ${ }^{1}$ which are spared in C4 tetraplegic patients ${ }^{2}$ but involved in this patient with C3 lesion.

Y Ogawa, R Sakakibara

Department of Neurology, Chiba University, Chiba, Japan

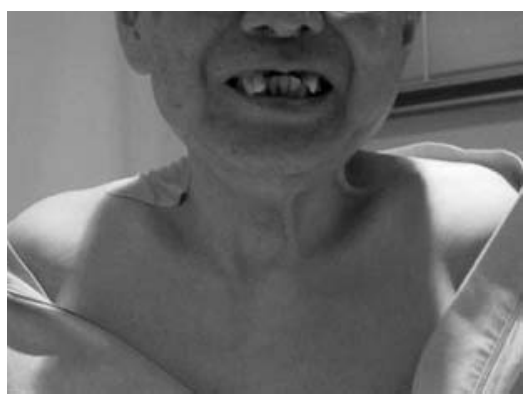

Figure 1 Platysma sign in high cervical lesion.

Correspondence to: Ryuji Sakakibara, Department of Neurology Chiba University, 18-1 Inohana Chuo-ku, Chiba 260-8670 Japan; sakakibara@faculty.chiba-u.jp

Consent was obtained for publication of figure 1 .

\section{References}

1 Chickering JG, Sokoloff AJ. Innervation of propatagial musculature in a flying squirrel, Glaucomys volans (Rodentia Sciuridae). Brain Behavior Evolution 1996:47:1-7.

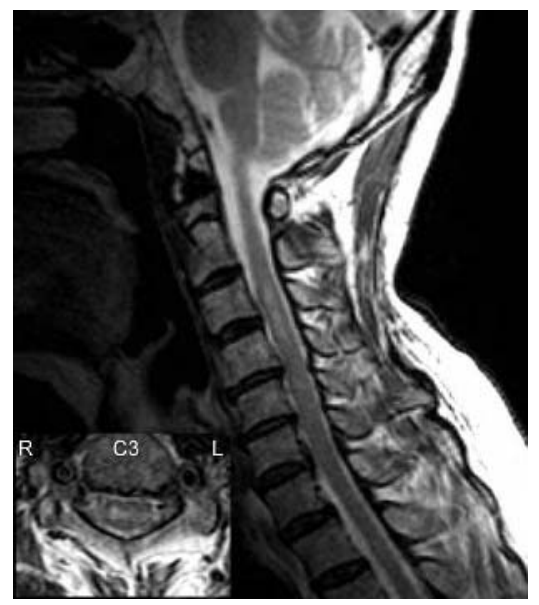

Figure $2 M R I$ scan of the patient.

2 Pollock D, Sell H. Myoelectric control sites in the high-level quadriplegic patient. Arch Phys Med Rehab 1978;59. 217-20. 